\title{
Detection and differentiation of Newcastle disease virus and influenza virus by using duplex real-time PCR
}

\author{
Dawid Nidzworski ${ }^{1 凶}$, Edyta Wasilewska', Krzysztof Smietanka², Bogusław Szewczyk \\ and Zenon Minta ${ }^{2}$ \\ 'Department of Molecular Virology, Intercollegiate Faculty of Biotechnology, University of Gdansk and Medical University of Gdansk, Gdańsk, \\ Poland; ${ }^{2 T h e ~ N a t i o n a l ~ V e t e r i n a r y ~ R e s e a r c h ~ I n s t i t u t e, ~ P u ł a w y, ~ P o l a n d ~}$
}

\begin{abstract}
Newcastle disease virus (NDV), member of the Paramyxoviridae family and avian influenza virus (AIV), member of the Orthomyxoviridae family, are two main avian pathogens causing serious economic problems in poultry health. Both are enveloped, single-stranded, negativesense RNA viruses and cause similar symptoms, ranging from sub-clinical infections to severe diseases, including decrease in egg production, acute respiratory syndrome, and high mortality. Similar symptoms hinder the differentiation of infection with the two viruses by standard veterinary procedures like clinical examination or necropsy. To overcome this problem, we have developed a new duplex real-time PCR assay for the detection and differentiation of these two viruses. Eighteen NDV strains, fourteen AIV strains, and twelve other (negative control) strains viruses were isolated from allantoic fluids of specific pathogen-free (SPF), embryonated eggs. Four-weeks-old SPF chickens were co-infected with both viruses (NDV - LaSota and AIV - H7N1). Swabs from cloaca and trachea were collected and examined. The results obtained in this study show that by using duplex real-time PCR, it was possible to detect and distinguish both viruses within less than three hours and with high sensitivity, even in case a bird was co-infected. Additionally, the results show the applicability of the real-time PCR assay in laboratory practice for the identification and differentiation of Newcastle disease and influenza $A$ viruses in birds.
\end{abstract}

Key words: Newcastle disease virus, influenza virus, detection, differentiation, real-time PCR, duplex

Received: 14 May, 2013; revised: 24 July, 2013; accepted:

01 September, 2013; available on-line: 13 September, 2013

\section{INTRODUCTION}

From the epidemiological and economic point of view, avian influenza and Newcastle disease are the most important poultry diseases all over the world.

Newcastle disease virus (NDV) belongs to the Mononegavirales order of the Paramyxoviridae family and Avulavirus genus. The viral particle is composed of a matrix protein, surface glycoproteins: hemagglutinin-neuraminidase and fusion protein and has a double lipid layer on its surface. The genome of NDV is linear, non-segmented, singlestranded RNA encoding 8 proteins (Lamb et al., 2005). NDV strains are classified into one of the three major pathotypes: velogenic, mesogenic, and lentogenic (Beard et al., 1984). The studies conducted by Rott and Klenk (1988) revealed the key role of a small amino acid motif (in position 112-117) at the cleavage site of F0 protein of NDV, in the molecular determination of pathotype. In highly virulent strains, the presence of $\mathrm{C}-{ }^{112} \mathrm{R} / \mathrm{K}-\mathrm{R}$ $\mathrm{Q}-\mathrm{K} / \mathrm{R}-\mathrm{R}-\mathrm{F}^{117}-\mathrm{N}$ motif makes them susceptible to cleavage by a common, subtilisin-like protease, which results in the easier spread throughout the host. The genome of low virulent strains contains less basic amino acids in the ${ }^{112} \mathrm{G} / \mathrm{E}-\mathrm{K} / \mathrm{R}-\mathrm{Q}-\mathrm{G} / \mathrm{E}-\mathrm{R}-\mathrm{L}^{117}$ motif, which is recognized only by trypsin-like proteases present mainly in the respiratory tract (Nagai et al., 1976; Collins et al., 1996). Highly virulent velogenic strains cause acute infections and high mortality. Mesogenic (intermediately virulent) strains cause respiratory disease in young chickens and decreased egg production, whereas lentogenic (avirulent) strains cause mild respiratory infection or give no symptoms in poultry (Seal et al., 1995).

Avian Influenza virus (AIV) is a member of the Orthomyxoviridae family. Similarly to NDV, AIV is a pleomorphic (composed with matrix protein), enveloped virus, containing linear, single-stranded RNA of negative polarity covered by nucleoprotein, but its genome is divided into 8 segments coding for 12 proteins. On the surface of the virion there are ion channels and two main glycoproteins: hemagglutinin and neuraminidase responsible for the diversity of the virus. Highly virulent HPAI (bighly pathogenic avian influenza) strains cause severe symptoms in respiratory tract, digestive, and nervous systems that lead to high mortality reaching up to $100 \%$. This group includes, in particular, some $\mathrm{H} 5$ and $\mathrm{H} 7$ influenza strains. Other strains cause milder symptoms: apathy, decreases in laying capacity, mild respiratory tract disorders, and are known as LPAI (low pathogenic avian influenza) (Alexander, 1993; Capua et al., 2002). The differences in virulence level have a molecular background. In order for the virus to be virulent, it is necessary to cleave the hemagglutinin precursor, HA0 into two sub-units. In the highly virulent strains, the cleavage site is modified by the insertion of additional basic amino acids in the process of homologous recombination. As a result, hemagglutinin of HPAI strains can be cleaved by the majority of enzymes present in various cells of the host organism, whereas hemagglutinin of LPAI strains can only be cleaved by trypsin-like enzymes present in digestive and respiratory tracts (Suarez et al., 2000).

Newcastle disease virus and avian influenza virus cause similar symptoms in infected birds, which makes

e-mail: dawid.nidzworski@biotech.ug.gda.pl

Abbreviations: AIV, Avian influenza virus; BQ, Blackberry Quencher $^{\oplus}$; BNDV, Newcastle disease virus; FAM, 6-carboxyfluorescein; TAMRA, 6-carboxytetramethylrhodamine; YAK, Yakima Yellow ${ }^{\circledast}$. 
a quick diagnosis difficult (Table 1). Symptoms are observed in digestive tract, respiratory tract, and nervous system. Incubation period lasts normally 2 to 6 days, and it depends on the level of virulence of a strain and condition of the bird. The most frequent clinical symptoms are: apathy, loss of appetite, diarrhoea, secretion from nostrils and beak, difficulties in breathing, rattle, strong convulsions, neck torsions, drooping wings, and paralysis. In internal organs, hemorrhagic lesions occur. Also, a significant drop in laying capacity and laying eggs without shells can be observed (Seal et al., 2000; Capua et al., 2002; Panda et al., 2004).

Traditional methods of isolation and identification of viruses, such as propagation in chicken embryos or cell culture followed by identification in hemagglutinationinhibition test (HI) are time consuming and laborious. Fast developing molecular biology tools are an alternative to traditional diagnostic methods and allow for fast and definite identification of a particular pathogen in a sample.

The tests developed to date are based mostly on PCR and RT-PCR methods, and most of them focus on the identification of only a few types of influenza serotypes (H3, H5, H7, and H9) and NDV. Primers used in those tests are based on specific fragments of hemagglutinin gene (for detection of influenza virus) and fusion (F) protein (for detection of NDV) (Mia Kim et al., 2008; Chen et al., 2008; Rashid et al., 2009; Tang et al., 2012).

In this study, by using the previously described, as well as newly developed primers for the detection of conserved fragments of both viruses, we present a new duplex real-time PCR assay for simultaneous detection and differentiation of avian influenza virus and Newcastle disease virus. The use of real-time PCR on conserved fragments of the genes of both viruses assures the versatility of this method and significantly shortens the analysis time when compared to traditional PCR.

\section{MATERIALS AND METHODS}

Virus strains and RNA extraction. NDV, AIV, and other strains that were analysed in this study are listed in Table 2. With the exception of A/ostrich/DenmarkQ/72420/96 and A/African starling/England/983/79 (source: AHVLA Weybridge, UK), all other strains were derived from the collection of National Veterinary Research Institute (Pulawy, Poland). APMV strains were

purchased from $\mathrm{x}-\mathrm{OvO}$ Limited (Dunfermline, United Kingdom). Reovirus (Reo S1133) and infectious bronchitis virus (IB $\mathrm{K}+4 / 91$ ) were components of Nobilis REO 1133 and Nobilis IB 4-91 vaccines (Intervet/ Schering-Plough Animal Health, Holland).

RNA was extracted from allantoic fluid of SPF, embryonated eggs (VALO-BioMedia, Germany) inoculated with AIV and NDV strains, in accordance with OIE Diagnostic Manual (OIE, 2009) using RNeasy Mini Kit (Qiagen, Valencia, CA, USA) protocol. Additionally, RNA samples from oral and cloacal swabs were isolated using the same kit.

Primers and probes design. In silico analyses were performed by means of the Geneious software (http://www.geneious.com/), using sequences available in GenBank (http://www.ncbi.nlm.nih.gov/genbank/). For the detection and differentiation of NDV and AIV, two sets of primers and two TaqMan probes were used. To detect influenza virus, primers and the probe described by Spackman et al. (2002) shown below (AIV-F, AIV-R, AIV-P), were used. However, the Tamra florophore was replaced with BBQ1. For Newcastle disease virus detection, a new set of primers and a new TaqMan probe were designed, based on the conserved fragment of $\mathrm{M}$ gene of NDV (NDV-F, NDV-R, NDV-P).

AIV-F (25-48):

AIV-R (101-124):

AIV-P (64-83):

NDV-F (4011-4030): 5' GTCCCAAATACCGGAGACCT 3'

NDV-R (4142-4162): 5' TTGTTTGCCACAACCCTACAG 3'

NDV-P (4116-4135): 5'-YAK-GTGCAGGCACCCCRAGTGCT-BBQ2-3'

where:

$\mathrm{R}=\mathrm{A}$ or $\mathrm{G}$; FAM - 6-carboxyfluorescein; YAK Yakima Yellow; BBQ - Blackberry Quencher.

BLAST sequence analyses were also performed to confirm the specificity of the designed primers.

cDNA synthesis and real-time PCR. Synthesis of the first strand of cDNA was carried out according to the procedure described for Transcriptor High Fidelity cDNA Synthesis Kit (Roche Diagnostics, Mannheim, Germany). The reaction mix containing viral RNA (5 $\mu \mathrm{l})$, random hexamer primers $(2 \mu \mathrm{l})$ and water $(4.5 \mu \mathrm{l})$

Table 1. Comparison of avian influenza virus and Newcastle disease virus

\begin{tabular}{|c|c|c|}
\hline Characteristic & Influenza virus type $\mathrm{A}$ & Newcastle disease virus \\
\hline Virus family & Orthomyxoviridae & Paramyxoviridae \\
\hline \multirow{2}{*}{ Type of genetic material } & \multicolumn{2}{|l|}{ Negative, single stranded RNA } \\
\hline & 8 segments & Non-segmented \\
\hline Shape & \multicolumn{2}{|l|}{ Spherical, variable } \\
\hline Envelope & \multicolumn{2}{|l|}{ present (lipid-protein) } \\
\hline Number of proteins & 12 & 8 \\
\hline Genome size & Approximately $13-14$ thousand nt & Approximately 15 thousand $\mathrm{nt}$ \\
\hline Virulence & $\begin{array}{l}\text { Depending on the cleavage site of fusion } \\
\text { protein (FO) }\end{array}$ & $\begin{array}{l}\text { Depending on the cleavage site of hemag } \\
\text { glutinin }(\mathrm{HAO})\end{array}$ \\
\hline Reservoir & \multicolumn{2}{|l|}{ Wild waterfowl (low virulent strains) } \\
\hline Clinical symptoms & \multicolumn{2}{|c|}{$\begin{array}{l}\text { Apathy, loss of appetite, diarrhoea, difficulties in breathing, strong convulsions, neck tor- } \\
\text { sion, drooping wings, paralysis, hemorrhagic lesions, decrease in laying capacity }\end{array}$} \\
\hline Incubation period & \multicolumn{2}{|l|}{$1-6$ days } \\
\hline
\end{tabular}


was incubated for $10 \mathrm{~min}$. at $65^{\circ} \mathrm{C}$. Subsequently, reaction buffer, RNase inhibitor, dNTPs, DTT, and reverse transcriptase were added. The final mixture contained: $1 \mathrm{x}$ reaction buffer $(250 \mathrm{mM}$ Tris $/ \mathrm{HCl}, 150 \mathrm{mM} \mathrm{KCl}, 40$ $\mathrm{mM} \mathrm{MgCl} ; \mathrm{pH} 8.5$ ), $20 \mathrm{U}$ of RNase inhibitor (in: 20 $\mathrm{mM}$ Heps-KOH, $50 \mathrm{mM} \mathrm{KCl}, 8 \mathrm{mM}$ DT'T, $50 \%$ glycerol; $\mathrm{pH}$ 7.6), $60 \mu \mathrm{M}$ of random hexamer primers, 1 $\mathrm{mM}$ of each dNTP, $5 \mathrm{mM}$ of DTT, and $10 \mathrm{U}$ of reverse transcriptase (in: $200 \mathrm{mM}$ potassium phosphate, $2 \mathrm{mM}$ DTT, $0.2 \%$ Triton X-100, 50\% glycerol, $\mathrm{pH} 7.2)$. It was then incubated for $30 \mathrm{~min}$. at $47^{\circ} \mathrm{C}$, followed by $5 \mathrm{~min}$. incubation at $85^{\circ} \mathrm{C}$, and cooled on ice.

Duplex real-time PCR was performed using LightCycler 2.0 $0^{\mathrm{TM}}$ (Roche Diagnostics, Mannheim, Germany). $10 \mu \mathrm{l}$ of the final mixture contained $9 \mu \mathrm{l}$ of the reaction mixture: 1x LC TaqMan Master (Roche Diagnostics, Mannheim, Germany), $0.3 \mu \mathrm{M}$ of each primer, $0.5 \mu \mathrm{M}$ of each TaqMan probe, and $1 \mu$ l of cDNA. A negative control lacking cDNA was also prepared. The samples were initially denatured at $95^{\circ} \mathrm{C}$ for $10 \mathrm{~min}$., followed by 45 cycles consisting of: $95^{\circ} \mathrm{C}$ (denaturation) for $10 \mathrm{sec}$., $54^{\circ} \mathrm{C}$ (annealing) for $15 \mathrm{sec}$, and $72^{\circ} \mathrm{C}$ (extension) for 7 sec. Fluorescence was measured at two wavelengths: 530 $\mathrm{nm}$ for AIV-P probe (FAM) and $560 \mathrm{~nm}$ for NDV-P probe (YAK).

Detection limit, cloning and specificity of the assay. The detection limit was determined using target copy number of fragments of $\mathrm{M}$ genes of both viruses. Conserved fragments of the LaSota strain of NDV and 467/06 H5N1 strain of avian influenza virus were cloned into pGEM-T easy vector (Promega, Madison, WI, USA). Plasmid DNA was extracted from bacteria using the Plasmid mini Kit (A\&A Biotechnology, Gdansk, Poland). The concentration of plasmid DNA was determined by spectrophotometry. DNA copy number was calculated using the formula described by $\mathrm{Ke}$ et al. (2006). The plasmid was serially 10 -fold diluted to serve as a standard for determining the sensitivity of the real-time PCR assay. cDNA was added to the reaction mixture as a template.

The duplex real-time PCR assay was compared with the previously published methods developed by Mia Kim et al. and Spackman et al. (Spackman et al., 2002; Mia Kim et al., 2008).

The specificity of the newly developed real-time PCR assay was investigated using the RNA extracted from NDV and AIV strains, as well as from 12 other avian viruses presented in Table 2.

Experimental infection. In order to check the new method on clinical samples, an experiment with co-infected chickens was performed. Four 4-weeks-old SPF chickens were infected intraocularly and intranasally with both viruses (NDV - LaSota and AIV - H7N1) in a $10^{7,5} \mathrm{EID}_{50}: 10^{6,0} \mathrm{EID}_{50}$ proportion. Swabs from cloaca and trachea were collected on the fourth and fifth day of the experiment and examined using the new method and two previously described tests (Spackman et al., 2002; Mia Kim et al., 2008).

\section{RESULTS}

\section{Detection and differentiation of NDV and AIV strains by duplex real-time PCR assay}

Eighteen strains of Newcastle Disease Virus (including ten lentogenic, two mesogenic, and six velogenic isolates) and fourteen Avian Influenza Virus strains were tested. By using the duplex real-time PCR test, it was possible to detect and differentiate both avian viruses. Influenza virus was detected using 530 $\mathrm{nm}$ channel of Light Cycler and NDV was detected in $560 \mathrm{~nm}$ channel. All thirty-two strains were detected with $\mathrm{Cp}$ values between 17.43 and 34.68 (Table 2).

\section{Analysis of experimentally infected birds}

Using the new test it was possible to detect and differentiate both viruses in a single reaction. Additionally, the assay was compared with previously published tests (Spackman et al., 2002; Mia Kim et al., 2008). The results show that the new method may be used as an alternative assay for the detection of NDV and AIV (Table 3).

\section{Sensitivity, specificity and detection limit of the real- time PCR assay}

The sensitivity of the new real-time PCR assay was investigated by analysing $32 \mathrm{NDV}$ and AIV strains, and all the templates from NDV and AIV strains gave distinctive products. The method proved to be specific since no amplification products were detected when 12 unrelated viruses were tested (Table 2).

The detection limit of this assay was assessed by analysing serial dilutions of plasmids carrying fragments of $\mathrm{M}$ genes of NDVs and AIVs. For the real-time PCR assay, the detection limits were $10^{2}$ copies of plasmid DNA per reaction for both viruses, even in co-infection. Any result with a $\mathrm{Ct}$ value higher than 40 was treated as unconvincing and was rejected.

\section{DISCUSSION}

In this study, we presented a new duplex real-time PCR assay for detection and differentiation of Avian Influenza and Newcastle Disease Virus. The test is based on fast and sensitive real-time PCR method with the use of TaqMan probes. The test utilizes previously described primers and a slightly modified probe for detection of influenza virus at $530 \mathrm{~nm}$ wavelength (Spackman et al., 2002). The primers were designed to detect the conserved fragment of the $7^{\text {th }}$ segment coding M1 and M2 proteins of influenza virus. Newcastle disease virus is detected at $560 \mathrm{~nm}$ wavelength, and the primers and the probe also were designed based on the conserved fragment coding matrix protein. Both genes in both viruses show the highest level of conservation, and therefore the test is versatile for detection of all AIV and NDV strains.

In previously described tests for differentiation of these two viruses, the authors selected the hemagglutinin gene for influenza virus and fusion protein gene for NDV. However, these genes are very variable, and the tests based on their detection may not be successful in some cases. Also, those tests focus on detection of particular subtypes of AIV (H3, H5, H7, and/or H9). Though they are very useful, they do not allow detection of other subtypes of influenza virus, which could be dangerous to wild and domestic birds (Chen et al., 2008; Rashid et al., 2009; Tang et al., 2012).

In the course of development and design of the primers, all types of NDVs and AIVs were taken into consideration. Real-Time PCR method is a very fast method of analysis (less than 1 hour) with very high sensitivity (10-100 copies of genetic material). The versatility and sensitivity of the test make it suitable for wide use in veterinary laboratories and for fast detection of both viruses in wild and domestic birds. 
Table 2. Duplex Real-time PCR analysis of viral strains.

Avian influenza and Newcastle disease viruses were analysed in different channels of LightCycler instrument, 530 nm (FAM florophore and $560 \mathrm{~nm}$ (YAK florophore), respectively.

\begin{tabular}{|c|c|c|c|c|}
\hline \multirow{2}{*}{ No } & \multirow{2}{*}{ Strain } & \multirow{2}{*}{ Pathotype/Lineage/Serotype } & \multicolumn{2}{|l|}{$\mathrm{Cp}$} \\
\hline & & & $530 \mathrm{~nm}$ & $560 \mathrm{~nm}$ \\
\hline 1 & Ulster $2 \mathrm{C}$ - reference & $\mathrm{L}(1)$ & - & 27.04 \\
\hline 2 & LaSota - reference AF077761 & $L(2)$ & - & 26.00 \\
\hline 3 & Clone 30 - commercial vaccine & $L(2)$ & - & 25.85 \\
\hline 4 & APMV-1/chicken/Poland/111/90 & $L(2)$ & - & 22.23 \\
\hline 5 & APMV-1/chicken/Poland/89/90 & $L(2)$ & - & 25.90 \\
\hline 6 & APMV-1/chicken/Poland/299/92 & $L(2)$ & - & 19.97 \\
\hline 7 & APMV-1/chicken/Poland/117/90 & $\mathrm{L}(2)$ & - & 28.37 \\
\hline 8 & APMV-1/chicken/Poland/548/04 & $L(2)$ & - & 17.43 \\
\hline 9 & APMV-1/turkey/Poland/549/04 & $L(2)$ & - & 23.10 \\
\hline 10 & APMV-1/chicken/Poland/18/91 & $L(2)$ & - & 29.96 \\
\hline 11 & APMV-1/chicken/Poland/Radom/70 & $V(3 b)$ & - & 28.15 \\
\hline 12 & Italy/2736/00 - reference AY562989 & $V(4 b)$ & - & 27.36 \\
\hline 13 & APMV-1/pigeon/Poland/AR1/95 (1995) & $V(4 b)$ & - & 34.64 \\
\hline 14 & APMV-1/pigeon/Poland/AR4/95 (1995) & $V(4 b)$ & - & 28.73 \\
\hline 15 & APMV-1/pigeon/Poland/AR5/92 (1992) & $V(4 b)$ & - & 31.95 \\
\hline 16 & APMV-1/pigeon/Poland/M470/05 & $\mathrm{V}(4)$ & - & 20.46 \\
\hline 17 & APMV-1/pigeon/Poland/AR2/95 (1995) & $M(4)$ & - & 33.95 \\
\hline 18 & APMV-1/pigeon/Poland/AR7/98 (1998) & $M(4)$ & - & 31.76 \\
\hline 19 & $\mathrm{~A} / \mathrm{mallard} /$ Poland/275/09/H2N? & $\mathrm{H} 2 \mathrm{~N} ?$ & 23.59 & - \\
\hline 20 & A/mallard/Poland/227/08/H3N3 & H3N3 & 21.72 & - \\
\hline 21 & A/mallard/Poland/214/09/H3N8 & H3N8 & 34.65 & - \\
\hline 22 & A/mallard/Poland/96/10/H3N9 & H3N9 & 31.80 & - \\
\hline 23 & A/buzzard/Poland/266B/07/H5N1 & $\mathrm{H} 5 \mathrm{~N} 1$ & 24.72 & - \\
\hline 24 & A/swan/Poland/467/06/H5N1 & H5N1 & 24.60 & - \\
\hline 25 & A/swan/Poland/937/06/H5N1 & $\mathrm{H} 5 \mathrm{~N} 1$ & 34.04 & - \\
\hline 26 & A/greylag goose/Poland/74/10/H5N2 & $\mathrm{H} 5 \mathrm{~N} 2$ & 20.70 & - \\
\hline 27 & A/ostrich/Denmark-Q/72420/96 (H5N2) & $\mathrm{H} 5 \mathrm{~N} 2$ & 30.79 & - \\
\hline 28 & A/African starling/England/983/79(H7N1) & H7N1 & 27.71 & - \\
\hline 29 & A/mallard/Poland/01/08/H7N7 & H7N7 & 25.24 & - \\
\hline 30 & A/mallard/Poland/16/06/H7N7 & H7N7 & 34.68 & - \\
\hline 31 & A/mallard/Poland/41/09/H7N7 & H7N7 & 32.63 & - \\
\hline 32 & A/common gull/Poland/241/11/H13N? & $\mathrm{H} 13 \mathrm{~N} ?$ & 23.37 & - \\
\hline 33 & APMV - 2 & NA & - & - \\
\hline 34 & APMV - 3 & NA & - & - \\
\hline 35 & APMV - 4 & NA & - & - \\
\hline 36 & APMV - 6 & NA & - & - \\
\hline 37 & APMV - 7 & NA & - & - \\
\hline 38 & APMV - 8 & NA & - & - \\
\hline 39 & APMV - 9 & NA & - & - \\
\hline 40 & Coronavirus 165/08 5-8 & NA & - & - \\
\hline 41 & Rotavirus G036/10 1-5 & NA & - & - \\
\hline 42 & Infectious bronchitis virus $131 / 92$ & NA & - & - \\
\hline 43 & Reovirus Reo S1133 (Nobilis REO 1133, Intervet) & NA & - & - \\
\hline 44 & IB K+ 4/91 (Nobilis IB 4-91, Internet) & NA & - & - \\
\hline
\end{tabular}

L, lentogenic; M, mesogenic; V, velogenic; NA, not applicable 


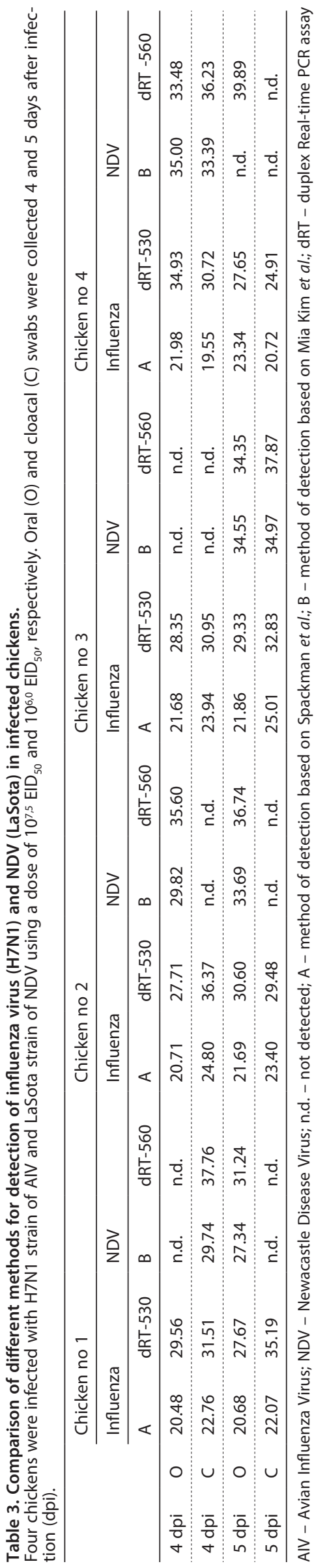

The advantage of the developed method is the ability to detect a broad spectrum of isolates as the primers and probes bind to the conserved fragment of $\mathrm{M}$ genes. However, it will be the first step of the whole and complete analysis of infected birds. The international regulations require a more precise characterization of the detected virus based on the virulence markers located on HA (AIV) or F (NDV) genes. Therefore, the method can serve as a useful screening tool, but all positive samples should be submitted to more scrutinized molecular testings, e.g. HA- and F-specific for determination of pathogenicity of NDV (Nidzworski et al., 2011) and AIV and its subtypes.

In conclusion, we describe a test, which allows for the detection and differentiation of two main avian pathogens - Newcastle disease virus and avian influenza virus, in one reaction, and in a relatively short time and give similar results to the reference methods. Conserved fragments of $\mathrm{M}$ genes used to design primers and probes make this method very universal. The test may serve as the first step of detection and assessment of virulence of NDVs and avian influenza viruses.

The present test can serve as a useful tool for monitoring of both viruses in the environment, controlling their spreading around the world and detecting co-infections in wild and domestic birds.

\section{Acknowledgments}

The authors wish to thank their colleagues from NVRI Pulawy, Poland: Monika Olszewska, Elzbieta Juszczuk, and Michal Jozwiak for technical support during the experiments.

This research work was supported by the European Union within the framework of the European Social Fund; Pomorskie Voivodeship "InnoDoktorant - Scholarships for PhD students, II edition.

\section{REFERENCES}

Alexander DJ (1993) Orthomyxovirus infections. In Viral Infections of Birds. McFerran JB, McNulty MS, eds, pp 287-316. Elsevier Science, London.

Beard CW, Hanson RP (1984) Newcastle disease. In Disease of Poultry, 8th edn. Hofstad MS, Barnes HJ, Calnek BW, Reid WM, Yoder HW, eds, pp 452-470. Iowa State University Press, Ames.

Capua I, Alexander DJ (2002) Avian influenza and human health. Acta Trop 83: 1-6.

Chen H, Zhang J, Sun D, Zhang D, Cai X, Liu X, Ding Y, Ma L, Yang S, Jin L, Liu Y (2008) Rapid discrimination of $\mathrm{H} 5$ and $\mathrm{H} 9$ subtypes of avian influenza viruses and Newcastle disease virus by multiplex RT-PCR. Vet Res Commun 32: 491-498.

Collins MS, Strong I, Alexander DJ (1996) Pathogenicity and phylogenetic evaluation of the variant Newcastle disease viruses termed "pigeon PMV-1 viruses" based on the nucleotide sequence of the fusion protein gene. Arch Virol 141: 635-647.

Ke GM, Cheng HL, Ke LY, Ji WT, Chulu JLC, Liao MH, Chang TJ, Liu HJ (2006) Development of a quantitative Light Cycler real-time RT-PCR for detection of avian reovirus. J Virol Methods 133: 6-13.

Lamb RA, Collins PL, Kolakofsky D, Melero JA, Nagai Y, Oldstone MBA, Pringle CR, Rima BK (2005) Family paramyxoviridae,. In Virus Taxonomy, VIIIth Report of the International Committee on Taxonomy of Viruses. Fauquet CM, Mayo MA, Maniloff J, Desselberger U, Ball LA, eds, pp 655-668. Elsevier Academic Press, San Diego.

Mia Kim L, Suarez DL, Afonso CL (2008) Detection of a broad range of class I and II Newcastle disease viruses using a multiplex real time reverse transcription polymerase chain reaction assay. J $V$ et $\mathrm{Di}$ agn Invest 20: 414-425.

Nagai Y, Klenk HD, Rott R (1976) Proteolytic cleavage of the viral glycoproteins and its significance for the virulence of Newcastle disease virus. Virology 72: 494-508.

Nidzworski D, Rabalski Ł, Gromadzka B (2011) Detection and differentiation of virulent and avirulent strains of Newcastle Disease Virus by real-time PCR. I Virol Methods 173: 144-149. 
OIE (2009) Manual of diagnostic tests and vaccines for terrestrial animals: mammals, birds and bees. In: Biological Standards Commission, World Organization for Animal Health, pp. 576-589. Paris.

Panda A, Huang Z, Elankumaran S, Rockemann DD, Samal SK (2004) Role of fusion protein cleavage site in the virulence of Newcastle disease virus. Microb Pathog 36: 1-10.

Rashid S, Naeem K, Ahmed Z, Saddique N, Abbas MA, Malik SA (2009) Multiplex polymerase chain reaction for the detection and differentiation of avian influenza viruses and other poultry respiratory pathogens. Poult Sci 88: 2526-2531.

Rott R, Klenk HD (1988) Molecular basis of infectivity and pathogenicity of Newcastle disease virus. In Newcastle Disease. Alexander DJ, eds, pp 98-112. Kluwer Academic Publishers, Boston, MA.

Seal BS, King DJ, Bennet JD (1995) Characterization of Newcastle disease virus isolates by reverse transcription PCR coupled to direct nucleotide sequencing and development of sequence database for pathotype prediction and molecular epidemiological analysis. J Clin Microbiol 33: 2624-2630.

Seal BS, King DJ, Sellers HS (2000) The avian response to Newcastle disease virus. Dev Comp Immunol 24: 257-268

Spackman E, Senne DA, Myers TJ, Bulaga LL, Garber LP, Perdue ML, Lohman K, Daum LT, Suarez DL (2002) Development of a Real-Time Reverse Transcriptase PCR Assay for Type A Influenza Virus and the Avian H5 and H7 Hemagglutinin Subtypes. I Clin Microbiol 40: 3256-3260

Suarez DL, Schultz-Cherry S (2000) Immunology of avian influenza virus: a review. Dev Comp Immunol 24: 269-283.

Tang Q, Wang J, Bao J, Sun H, Sun Y, Liu J, Pu J (2012) A multiplex RT-PCR assay for detection and differentiation of avian H3, H5, and $\mathrm{H} 9$ subtype influenza viruses and Newcastle disease viruses. I Virol Methods 181: 164-169. 